\title{
The hypotensive response to oral fat is comparable but slower compared with carbohydrate in healthy elderly subjects
}

\author{
Renuka Visvanathan ${ }^{1,2 *}$, Michael Horowitz ${ }^{1}$ and Ian Chapman $^{1}$ \\ ${ }^{1}$ Department of Medicine, University of Adelaide, Adelaide, South Australia \\ ${ }^{2}$ Aged and Extended Care Service, The Queen Elizabeth Hospital, Woodville South, Adelaide, South Australia \\ (Received 19 April 2005 - Revised 27 September 2005 - Accepted 27 September 2005)
}

\begin{abstract}
The objective of the present study was to determine the comparative hypotensive responses to drinks containing predominantly fat and carbohydrate $(\mathrm{CHO})$ in healthy elderly subjects. Using a randomised, cross-over study, the participants, twelve elderly subjects, six of them female (72.2 (SD 5.7) years), were investigated. On three separate days, blood pressure (BP) and heart rate were measured following ingestion of $300 \mathrm{ml}$ drinks containing: (1) CHO (75 g glucose and $93 \mathrm{~g}$ Polyjoule (CHO polymer) providing 2732 kJ (653 kcal)); (2) $88 \%$ fat (cream blended with milk providing $2732 \mathrm{~kJ}(653 \mathrm{kcal}))$; (3) water. Systolic BP decreased following the CHO drink $(P<0 \cdot 001)$ and the high-fat drink $(P<0 \cdot 001)$ but not water; there was no difference in the magnitude of the decrease between the $\mathrm{CHO}$ drink and the drink containing fat (13.4 $v$. $15 \cdot 6 \mathrm{mmHg})$. However, the onset of the fall was slower after the fat-containing drink $(13.0 \mathrm{v} .26 .5 \mathrm{~min}(P=0 \cdot 01)$; area under the curve for $0-30$ min for $\mathrm{CHO}$ drink $-6.5 v$. fat-containing drink $125.4 \mathrm{mmHg} \times \min (P=0.043)$ ). We conclude that ingestion of a high-fat drink results in a comparable fall in $\mathrm{BP}$ to a $\mathrm{CHO}$ drink although the onset is relatively slower. These observations may have implications for the management of postprandial hypotension.
\end{abstract}

Postprandial hypotension: Blood pressure: Elderly

Postprandial hypotension (PPH), defined as a decrease in systolic blood pressure (SBP) of $20 \mathrm{mmHg}$ or more within $2 \mathrm{~h}$ of the start of a meal, occurs frequently (prevalence 20-45\%) and represents a major cause of morbidity in older individuals (Jansen \& Lipsitz, 1995; Smith et al. 2003). Although it has been established that older individuals and patients with autonomic neuropathy (most frequently due to diabetes) who have PPH are at increased risk for falls, syncope, angina and transient ischaemic attacks, patients presenting with these symptoms are rarely assessed for PPH. Current approaches to the management of PPH are also suboptimal (Jansen \& Lipsitz, 1995).

Macronutrient composition is known to be an important determinant of the hypotensive response to a meal (Jansen \& Lipsitz, 1995). It is frequently stated that ingestion of carbohydrate $(\mathrm{CHO})$, particularly glucose, sucrose and to a lesser degree starch, but not fructose or xylose, lowers blood pressure (BP) more than ingestion of fat, protein or water (Mathias et al. 1989; Jansen et al. 1990; Heseltine et al. 1991; Visvanathan et al. 2005). However, it should be recognised that only a limited number of studies have been performed and some of the reported observations are inconsistent, particularly in relation to the effects of fat on BP (Hoeldtke et al. 1985; Potter et al. 1989; Jansen et al. 1990; Sidery et al. 1993; Jansen \& Lipsitz, 1995). Two studies involving older individuals ( $>60$ years) performed more than a decade ago found that ingestion of high-fat meals or drinks were not associated with significant falls in BP in contrast to CHO-containing meals (Potter et al. 1989; Jansen et al. 1990). In contrast to this, several other studies have shown a fall in BP following a high-fat meal (Hoeldtke et al. 1985; Bannister et al. 1987; Sidery et al. 1993).

Therefore, the effect of a high-fat meal on BP in older individuals is currently not clearly defined and this has both therapeutic and research implications. The aim of the present study was to evaluate the effects of high-fat and - $\mathrm{CHO}$ drinks on post-ingestion BP in healthy old individuals (water being the control drink).

\section{Methods \\ Subjects}

Twelve healthy, elderly subjects (six female) were recruited by advertisement. The mean age was 72.2 (SD 5.7) years and the BMI was 24.6 (SD 1.8) $\mathrm{kg} / \mathrm{m}^{2}$. All subjects were non-smokers and had no history of gastrointestinal disease or surgery, diabetes mellitus, significant respiratory disease or CVD, autonomic dysfunction, chronic alcohol abuse or epilepsy. No subject was taking medication known to influence $\mathrm{BP}$ and all medications remained unchanged during the study. 


\section{Protocol}

Each subject had BP, heart rate (HR) and blood glucose measurements on $3 \mathrm{~d}$ separated by at least $72 \mathrm{~h}$, before and after ingestion of the following drinks (all $300 \mathrm{ml}$ ):

(1) a $\mathrm{CHO}$ drink made from $75 \mathrm{~g}$ glucose and $93 \mathrm{~g} \mathrm{CHO}$ polymer (Polyjoule; Nutricia Pty Ltd, Castle Hill, NSW, Australia) (100\% CHO content; total energy $2732 \mathrm{~kJ}$ $(653 \mathrm{kcal}))$ plus lemon flavouring;

(2) a high-fat drink made from $110 \mathrm{ml}$ rich cream blended with $190 \mathrm{ml}$ full-cream milk $(88 \%$ fat, $7 \%$ CHO (mostly lactose), $5 \%$ protein; total energy $2732 \mathrm{~kJ}$ (653 kcal)) with low-energy flavouring;

(3) tap water (control).

The studies were randomised but not blinded and separated by at least $72 \mathrm{~h}$. All drinks were served at a temperature of $22^{\circ} \mathrm{C}$ to avoid the potential effect of temperature on BP (Kuipers et al. 1991).

On the study days, subjects attended the Department of Medicine following an overnight fast $(10 \mathrm{~h}$ for solids with small sips of water permitted until 06.00 hours). In individual subjects, all three studies were performed at the same time. Subjects were seated comfortably in a chair. An intravenous cannula was inserted (left cubital fossa) and a BP cuff was attached to the right upper arm. Cardiovascular autonomic function was evaluated first thing in the morning on one of the study days. Each subject provided written, informed consent and the study was approved by the research ethics committee of the Royal Adelaide Hospital.

\section{Measurements}

Blood pressure and heart rate. $\mathrm{SBP}$, diastolic $\mathrm{BP}(\mathrm{DBP})$ and HR were measured using an automated oscillometric BP monitor (DINAMAP ProCare; GE Medical Systems, Sydney, NSW, Australia). Following a 20 min 'rest' post-cannula insertion, three measurements were obtained at 9, 6 and 3 min before drinks ingestion $(t=0)$. The mean of these three readings formed the 'baseline' value $(t=0)$. The study drink was consumed within $3 \mathrm{~min}$ and so the first measurement post-drink ingestion was at $\mathrm{t}=3 \mathrm{~min}$. $\mathrm{BP}$ and $\mathrm{HR}$ measurements were then measured every $3 \mathrm{~min}$ for $90 \mathrm{~min}$ (to $\mathrm{t}=90 \mathrm{~min}$ ) post-drink ingestion.

Blood glucose. Venous blood was obtained from the intravenous cannula for glucose estimation at baseline and $\mathrm{t}=5$, $10,15,30,45,60,75$ and $90 \mathrm{~min}$. Blood glucose was determined using a glucometer (True Sense; Abbott Diagnostic Division, Botany, NSW, Australia).

Total triacylglycerols. Plasma total triacylglycerol concentrations were measured in stored $\left(-70^{\circ} \mathrm{C}\right)$ plasma samples. Only samples from eleven subjects and limited time-points $(\mathrm{t}=0,15,30,60$ and $90 \mathrm{~min})$ were available for analysis. Plasma was processed on an Olympus 5400 analyser using triacylglycerols-liquid reagent (Integrated Sciences Pty. Ltd, Willoughby, NSW, Australia) at the Institute of Medical and Veterinary Science Laboratories in Adelaide, South Australia.

Autonomic function. Autonomic nerve function was evaluated using standardised cardiovascular reflex tests (Ewing \& Clarke, 1982; Piha, 1991). Parasympathetic function was evaluated by the variation $(\mathrm{R}-\mathrm{R}$ interval) of the HR during deep breathing and upon standing $(\mathrm{R}-\mathrm{R}$ interval at beat $30 / \mathrm{R}-\mathrm{R}$ interval at beat 15). Sympathetic function was assessed by the fall in SBP in response to standing. Each of the test results was scored according to age-adjusted predefined criteria as $0=$ normal, $1=$ borderline, and $2=$ abnormal for a total maximum score of 6 . A score $>3$ was considered to indicate autonomic dysfunction (Ewing \& Clarke, 1982; Piha, 1991; Jones et al. 2001).

\section{Statistical analysis}

All values are expressed as means and standard deviations. Two-way repeated measures ANOVA was used to examine the overall effects of time and types of drink (treatment) and the treatment $\times$ time interaction on changing BP and HR from baseline. One-way repeated measures ANOVA were conducted to evaluate the effects of each drink on BP, HR, blood glucose and total triacylglycerols over the first $90 \mathrm{~min}$. One-way repeated measures ANOVA were also conducted to compare the differences between the baseline BP, HR, blood glucose and total triacylglycerols values between the study days. The time to BP decrease was defined as the first time-point after drink ingestion when the SBP was less than baseline; the maximum fall in $\mathrm{BP}$ was the lowest value. The $\mathrm{BP}$ and $\mathrm{HR}$ areas under the curve (AUC) following the $\mathrm{CHO}$ and high-fat drink ingestion at $\mathrm{t}=0-30, \mathrm{t}=33-60$ and $\mathrm{t}=63-90 \mathrm{~min}$ were also determined using the trapezoidal method. These values derived for $\mathrm{CHO}$ and fat were then compared using paired Student's $t$ tests. All analyses were performed using Statview version 5.0 (SAS Institute Inc., Cary, NC, USA) and SuperANOVA (Abacus Concepts Inc., Berkeley, CA, USA). $P$ values $<0.05$ were considered statistically significant.

\section{Results}

The study drinks were all well tolerated. No subject had autonomic dysfunction (mean score $0 \cdot 9+0 \cdot 8$ ).

\section{Blood pressure}

There were no significant differences in the baseline BP (SBP (CHO drink 120.6 (SD 13.5) v. high-fat drink 121.5 (SD 15.44) v. water 120.7 (SD 14.6) $\mathrm{mmHg} ; P=0.93$ ) and $\mathrm{DBP}$ (CHO drink 66.2 (SD 7.11) v. high-fat drink 67.0 (SD 7.9) $v$. water 64.9 (SD 7.8) mmHg; $P=0.84$ ) ) between the study days. Three subjects had PPH (one following both the CHO and high-fat drinks, one following the $\mathrm{CHO}$ drink and another after the fat-containing drink); in all cases the PPH was asymptomatic.

For SBP (change from baseline), there were significant treatment $(P=0.04)$ and time $(P<0.001)$ effects and treatment $\times$ time interaction $(P<0.001)$ over the first $90 \mathrm{~min}$. SBP decreased from baseline following $\mathrm{CHO}$ drink $(P<0.001$; maximum fall 13.4 (SD 7.4) $\mathrm{mmHg}$ ) and high-fat drink $(P<0 \cdot 001$; maximum fall 15.6 (SD 10.5) $\mathrm{mmHg}$ ) ingestion to a similar extent but not after water $(P=0 \cdot 11)$. While there was no difference $(P=0.47)$ in the maximum fall between the $\mathrm{CHO}$ and high-fat drinks, the decrease in SBP was evident earlier after $\mathrm{CHO}$ than high-fat drink ingestion (13.0 (SD 11.7) v. 26.5 (SD 17.1) min; $P=0.01$ ). Consistent 
with this, the AUC for SBP following $\mathrm{CHO}$ and high-fat drink ingestion between 0 and $30 \mathrm{~min}$ were -6.5 (SD 137.6) and $125 \cdot 4(\mathrm{SD} 258 \cdot 3) \mathrm{mmHg} \times$ min respectively $(P=0.043)$. There was no significant difference in the SBP AUC between 33 and $60 \mathrm{~min}$ following $\mathrm{CHO}$ and high-fat drink ingestion $(-116.4$ (SD 178.7) v. -138.8 (SD 255.4) $\mathrm{mmHg} \times \mathrm{min}$; $P=0.749$ ). SBP had not returned to baseline at $90 \mathrm{~min}$ (Fig. 1 (a)).

For DBP (change from baseline) there were also significant treatment and time effects and treatment $\times$ time (all $P<0.001$ ) interaction. In the first $90 \mathrm{~min}$, DBP (Fig. 1 (b)) decreased from baseline to a similar extent following the $\mathrm{CHO}$ drink $(P<0.001$; maximum fall 10.2 (SD 3.5$) \mathrm{mmHg}$ ) and the high-fat drink $(P<0.001$; maximum fall 10.9 (SD 3.6) $\mathrm{mmHg})$ but not after water $(P=0.85)$. While there was no difference $(P=0.68)$ in the magnitude of the fall, the decrease in DBP occurred earlier following $\mathrm{CHO}$ than high-fat drink ingestion (10 (SD 5.3) v. 15 (SD 9.7) min; $P=0.01$ ). Consistent with this, the AUC for DBP following $\mathrm{CHO}$ and high-fat drink ingestion between 0 and $30 \mathrm{~min}$ were -49.8 (SD 79.0) and 17.8 $(\mathrm{SD} 100.4) \mathrm{mmHg} \times \min$ respectively $(P=0.08)$. There was no significant difference in the DBP AUC between 33 and $60 \mathrm{~min}$ following $\mathrm{CHO}$ and fat-containing drink ingestion $(-131.7$ (SD 87.2) v. $-138.6(\mathrm{SD} 112.2) \mathrm{mmHg} \times \mathrm{min}$; $P=0 \cdot 87$ ). DBP following $\mathrm{CHO}$ and high-fat drink ingestion had not returned to baseline at $90 \mathrm{~min}$ (Fig. 1 (b)).

\section{Heart rate}

There was no significant difference in baseline HR (CHO drink 61.3 (SD 8.3) $v$. high-fat drink 64.1 (SD 8.3) $v$. water 63.8 (SD 9.3) beats per $\min ; P=0.84$ ). There were significant treatment and time effects and treatment $\times$ time interaction (all $P<0.001$ ). HR increased following the $\mathrm{CHO}$ and fat-containing drinks $(P<0 \cdot 001)$ and decreased following water ingestion $(P<0.001)$ (Fig. 2). The rise in HR occurred sooner following the $\mathrm{CHO}$ drink than the high-fat drink (CHO drink 3.8 (SD 2.6) v. highfat drink 21.3 (SD 13.1) $\mathrm{min} ; P=0.001)$ and the magnitude of the rise was greater (AUC 0-30 min $\mathrm{CHO}$ drink 90.4 (SD 74.0) v. high-fat drink 8.6 (SD 43.1); $P=0.010$; AUC 33-60 min CHO drink 116.1 (SD 98.9) v. high-fat drink 64.8 (SD 51.5) beats; $P=0.062$ ). Following $\mathrm{CHO}$ and high-fat drink ingestion HR was still elevated at $90 \mathrm{~min}$ (Fig. 2).

\section{Blood glucose}

There were no significant differences in baseline blood glucose $(\mathrm{CHO}$ drink $5.7 v$. fat-containing drink $5.8 v$. water $5.8 \mathrm{mmol} / \mathrm{l} ; P=0.94)$. Blood glucose increased following the CHO drink $(P<0.001)$ but not after the high-fat drink $(P=0.55)$ or water $(P=0.83)$ (Fig. 3).

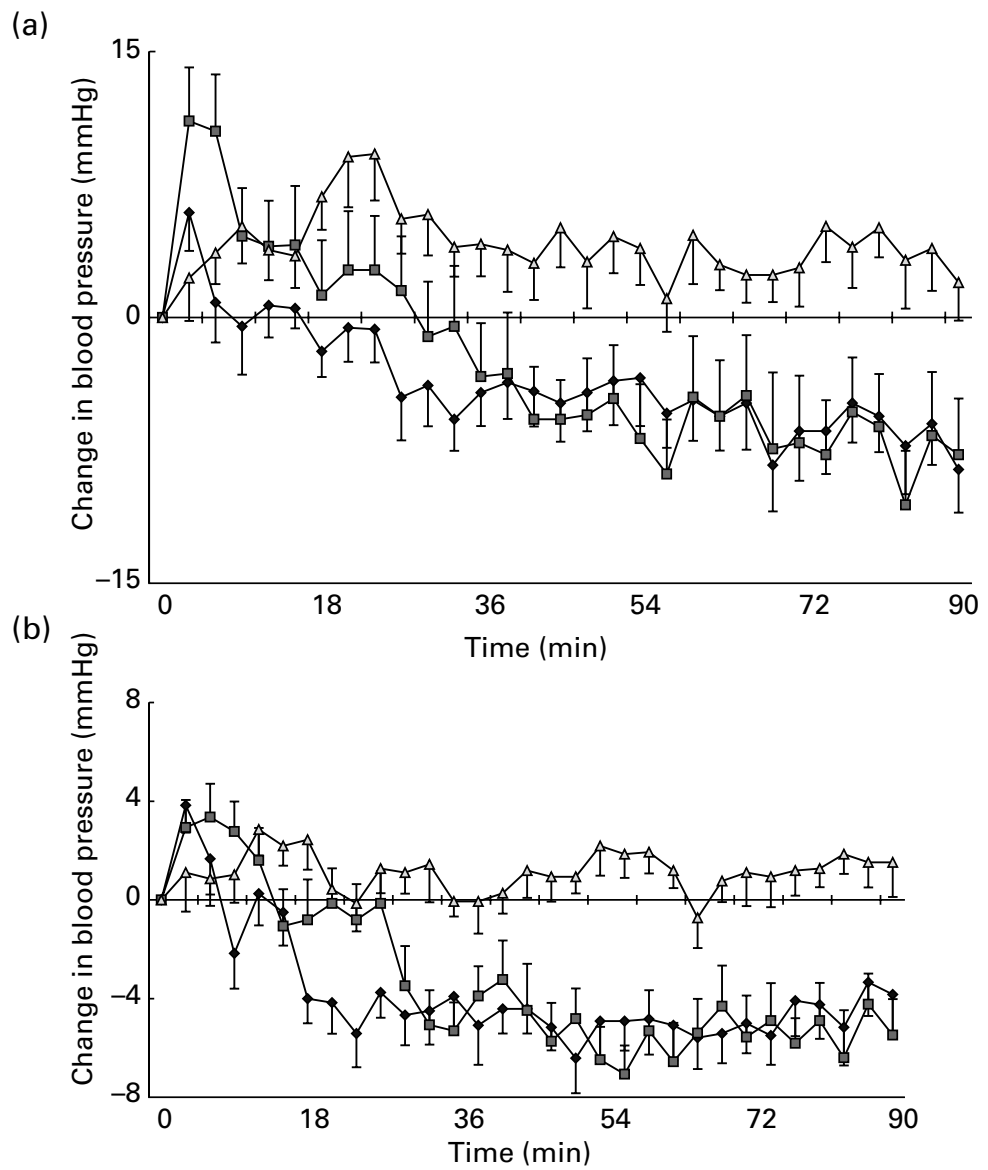

Fig. 1. Systolic (a) and diastolic (b) blood pressure expressed as changes from baseline following ingestion of $300 \mathrm{ml}$ drinks containing carbohydrate (- - ), $88 \%$ fat $(-\square-)$ and water $(-\triangle-)$. Values are means for twelve subjects, with standard errors represented by vertical bars. 


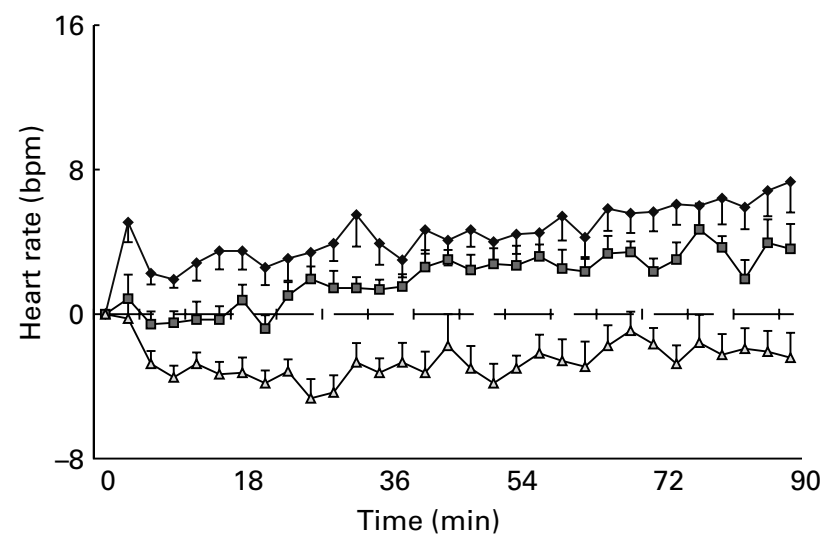

Fig. 2. Heart rate (beats per min; bpm) expressed as changes from baseline following ingestion of $300 \mathrm{ml}$ drinks containing carbohydrate $(--), 88 \%$ fat $(-\square-)$ and water $(-\triangle-)$. Values are means for twelve subjects, with standard errors represented by vertical bars.

\section{Total triacylglycerols}

There were no significant differences in baseline total triacylglycerol values $(\mathrm{CHO}$ drink $1.1 v$. fat-containing drink $1.2 v$. water $1.2 ; P=0.628)$. Total triacylglycerols values increased from baseline following the high-fat drink $(P=0.001)$ but not after the CHO drink $(0 \cdot 61)$ or water $(0 \cdot 26)$. A significant rise in plasma triacylglycerols following fat ingestion occurred somewhere between $\mathrm{t}=30$ and $\mathrm{t}=60 \min$ (values at $\mathrm{t}=30 \mathrm{v}$. baseline $P=0.067$ and values at $\mathrm{t}=60 \mathrm{v}$. baseline $P=0.005$ ) (Fig. 4).

\section{Discussion}

The present study has demonstrated that in unselected healthy elderly subjects, ingestion of a high-fat drink decreases SBP substantially (mean maximum fall of $17 \mathrm{mmHg}$ ) and as much as an isoenergetic $\mathrm{CHO}$ load of the same volume, but the onset of the decrease is slower. Also, the ingestion of nutrient-containing meals (i.e. the $\mathrm{CHO}$ and high-fat drinks) results in a HR increase whilst the ingestion of water is associated with a decrease in HR (Joannides et al. 1999; Routledge et al. 2002; Visvanathan et al. 2004; O'Donovan et al. 2005). Confirming the results of a previous study by our group, the $\mathrm{BP}$ response to a meal is not related to changes in blood glucose measurements (Visvanathan et al. 2004).

The observed trend for an increase in BP and fall in HR after water is consistent with previous studies and is presumably mediated by gastric distension leading to an increase in sympathetic vasoconstriction and cardiac vagal activity (Joannides et al. 1999; Routledge et al. 2002; Shannon et al. 2002). Where oral glucose ingestion leads to a fall in BP, intravenous infusion of glucose has less, if any, effect, indicating that the response is mediated from the gastrointestinal tract (Jansen \& Hoefnagels, 1987). This and the observation that BP falls in response to oral glucose ingestion in patients with type 1 diabetes (insulin-dependent) argue against a significant role for insulin in the pathophysiology of PPH (Jansen \& Hoefnagels, 1987; Stevens et al. 1991). In older individuals with PPH, the magnitude and duration of hypotension in response to equalvolume $\mathrm{CHO}$ drinks are both progressively greater with increasing CHO loads $(25 \mathrm{~g}$ v. $65 \mathrm{~g}$ v. $125 \mathrm{~g}$ ) (Vloet et al.

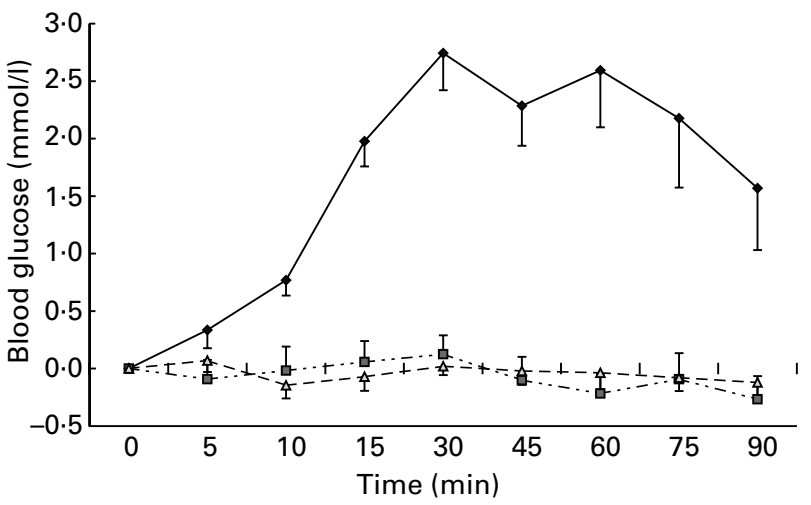

Fig. 3. Blood glucose concentration expressed as changes from baseline following ingestion of $300 \mathrm{ml}$ drinks containing carbohydrate $(-\downarrow-), 88 \%$ fat $(-\square-)$ and water $(-\triangle-)$. Values are means for twelve subjects, with standard errors represented by vertical bars.

2001). Currently, it is widely believed that the hypotensive effects of nutrient-containing meals are related predominantly to their $\mathrm{CHO}$ content and that fat has very little effect (Potter et al. 1989; Jansen et al. 1990; Jansen \& Lipsitz, 1995; Jones et al. 2001). The fall of BP following the ingestion of the high-fat meals in the present study contradicts this and this has research and therapeutic implications.

The observation that ingestion of a high-fat drink resulted in a fall in BP of similar magnitude to $\mathrm{CHO}$ was unexpected as in a previous study of ten hypertensive older individuals, a similar high-fat drink did not induce a fall in BP (Jansen et al. 1990). However, falls in BP following high-fat meals and drinks have been demonstrated in small numbers of young patients (less than six) with autonomic dysfunction (Hoeldtke et al. 1985; Bannister et al. 1987). In one other study evaluating BP changes following high-fat meals in older individuals, only a fall in DBP was seen (no SBP fall; Sidery et al. 1993). The fall in BP observed after the highfat drink in the present study is unlikely to be due to the small amount (7\%; $192 \mathrm{~kJ}$ (46 kcal)) of CHO (mainly lactose), particularly as we have previously demonstrated that

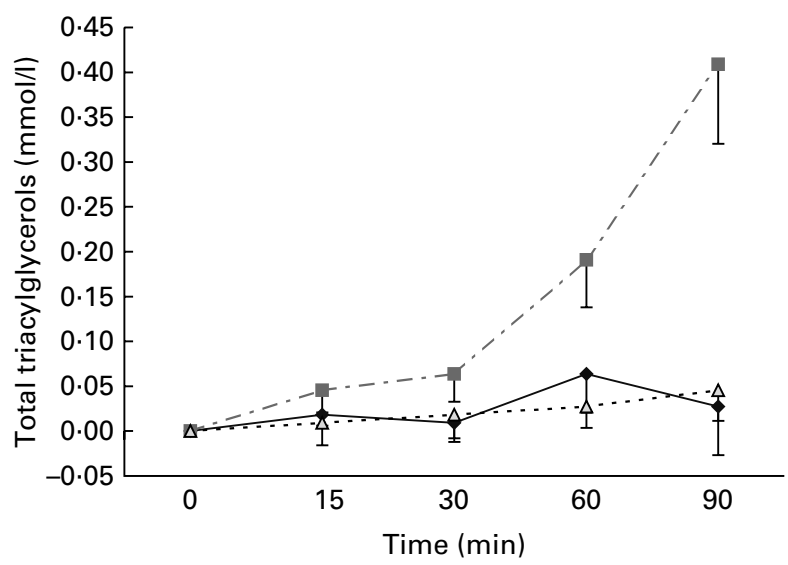

Fig. 4. Plasma total triacylglycerol concentration expressed as changes from baseline following ingestion of $300 \mathrm{ml}$ drinks containing carbohydrate $(-\downarrow-)$, $88 \%$ fat $(-\square-)$ and water $(-\triangle-)$. Values are means for twelve subjects, with standard errors represented by vertical bars. 
intraduodenal infusion of a greater amount of glucose $(4 \cdot 2(1 \mathrm{kcal}) / \mathrm{min}$ for $60 \mathrm{~min}(251(60 \mathrm{kcal})))$ has no effect on $\mathrm{BP}$ or HR in healthy elderly individuals, whereas BP falls and HR increases in response to an infusion rate of $12.6 \mathrm{~kJ}$ (3 kcal)/min (O'Donovan et al. 2002).

The pathophysiology of PPH is currently not clearly defined. The ingestion of nutrient-containing meals such as fatty and $\mathrm{CHO}$ meals are associated with increases in splanchnic blood flow, muscle sympathetic nerve activity and cardiac output in most studies (Hawley \& Channer, 1992; Waaler \& Eriksen, 1992; Fagius \& Berne, 1994). Failure in BP homeostasis involving either one or a combination of the cardiac system (i.e. cardiac output), vascular system (i.e. splanchnic blood flow), nervous system (i.e. muscle sympathetic nerve activity), gastric system (i.e. gastric emptying) or hormonal system is very likely (Jansen \& Lipsitz, 1995). A limitation of the present study was that none of these systems were evaluated and so the exact cause for the postprandial BP decrease in the study could not be defined.

We speculate that the hypotensive response to fat is mediated by fat digestion products and that the delayed hypotensive response to fat compared with $\mathrm{CHO}$ reflects the time taken for the generation of a sufficient quantity of NEFA to trigger this response. In support of this, the fall in SBP following fat ingestion appeared to correspond with the rise in total triacylglycerols (at approximately $30 \mathrm{~min}$ ). This hypothesis is further supported by the results of recent studies by our group. In one study, the fall in BP following oral sucrose was comparable with glucose but slower, suggesting that digestion of sucrose to glucose may be necessary to produce this effect (Visvanathan et al. 2005). In support of this, in another study, co-administration of arcabose, an $\alpha$-glucosidase inhibitor, with sucrose attenuated this fall in blood pressure (Gentilcore et al. 2005). In a similar manner, inhibition of fat digestion may attenuate the postprandial BP fall. This requires further evaluation.

In the present study fat and $\mathrm{CHO}$ ingestion was associated with a rise in HR. As with the BP changes, the rise in HR occurred later following fat ingestion than $\mathrm{CHO}$ ingestion. Similar rises in HR have been observed in other studies by our group following $\mathrm{CHO}$ ingestion although, to date, its role in the development of PPH is currently not known (Jones et al. 2001; O'Donovan et al. 2002). It may be that this rise in HR is a reflection of compensatory measures (i.e. increased cardiac output) in response to splanchnic pooling. With nutrient ingestion, there is increased mesenteric blood flow, increased cardiac output and redistribution of blood flow in favour of the gut (Waaler \& Eriksen, 1992; Hoost et al. 1996). In the present study also, there was a fall in HR following water ingestion. Water (devoid of nutrients) ingestion does not result in increased mesenteric blood flow (Waaler \& Eriksen, 1992). Instead, water ingestion is associated with an increase in sympathetic vasoconstrictor activity and increased cardiac vagal activity (Joannides et al. 1999; Routledge et al. 2002).

The changes in blood glucose measurements following fat, $\mathrm{CHO}$ and water ingestion was as expected (Erdmann et al. 2004; Visvanathan et al. 2004). Fat and CHO ingestion were associated with similar changes in BP but discrepant changes in blood glucose measurement. As in our previous study, there was no association between postprandial BP changes and postprandial changes in blood glucose measurements (Visvanathan et al. 2004).

In conclusion, the ingestion of a high-fat drink resulted in a similar, although delayed, fall in $\mathrm{BP}$ and rise in $\mathrm{HR}$ to a $\mathrm{CHO}$ drink. Hence, the presence of both fat and $\mathrm{CHO}$ in the intestine results in a fall in BP and may contribute to the development of PPH in those at risk. The slower onset of the decrease in BP after fat than CHO may indicate that lipolysis of fat is a prerequisite for its blood pressure-lowering effect. If so, inhibition of fat digestion may ameliorate this fall in BP. This may have therapeutic importance and warrants further evaluation. The results of the present study also need to be confirmed in a population with confirmed $\mathrm{PPH}$.

\section{Acknowledgements}

The present study was supported by a National Health and Medical Research Council of Australia research grant.

\section{References}

Bannister R, da Costa DF, Forster S \& Mathias CJ (1987) Cardiovascular effects of lipid and protein meals in autonomic failure. $J$ Physiol 377, 62 .

Erdmann J, Topsch R, Lippl F, Gussmann P \& Schusdziarra V (2004) Postprandial response of plasma ghrelin levels to various test meals in relation to food intake, plasma insulin, and glucose. J Clin Endocrinol Metab 89, 3048-3054.

Ewing DJ \& Clarke BF (1982) Diagnosis and management of diabetic autonomic neuropathy. Br Med J (Clin Res Ed) 285, 916-918.

Fagius J \& Berne C (1994) Increase in muscle nerve sympathetic activity in humans after food intake. Clin Sci (Lond) 86, 159-167.

Gentilcore D, Bryant B, Wishart JM, Morris HA, Horowitz M \& Jones KL (2005) Acarbose attenuates the hypotensive response to sucrose and slows gastric emptying in the elderly. Am J Med 118, 1289.

Hawley SK \& Channer KS (1992) Relative effects of fat-, carbohydrate- and protein-containing liquid diets on cardiac output in healthy adult subjects. Clin Sci (Lond) 83, 483-487.

Heseltine D, Dakkak M, Macdonald IA, Bloom SR \& Potter JF (1991) Effects of carbohydrate type on postprandial blood pressure, neuroendocrine and gastrointestinal hormone changes in the elderly. Clin Auton Res 1, 219-224.

Hoeldtke RD, O'Dorisio TM \& Boden G (1985) Prevention of postprandial hypotension with somatostatin. Ann Intern Med 103, 889-890.

Hoost U, Kelbaek H, Rasmusen H, Court-Payen M, Christensen NJ, Pedersen-Bjergaard U \& Lorenzen T (1996) Haemodynamic effects of eating: the role of meal composition. Clin Sci (Lond) 90, 269-276.

Jansen R \& Hoefnagels W (1987) Hypotensive and sedative effects of insulin in autonomic failure. $\mathrm{Br}$ Med $J$ (Clin Res Ed) 295, $671-672$.

Jansen RW \& Lipsitz LA (1995) Postprandial hypotension: epidemiology, pathophysiology, and clinical management. Ann Intern Med 122, 286-295.

Jansen RW, Peeters TL, van Lier HJ \& Hoefnagels WH (1990) The effect of oral glucose, protein, fat and water loading on blood pressure and the gastrointestinal peptides VIP and somatostatin in hypertensive elderly subjects. Eur J Clin Invest 20, 192-198.

Joannides R, Moore N, de la Gueronniere V \& Thuillez C (1999) Effect of water on arteries. Lancet 354, 516.

Jones KL, MacIntosh C, Su YC, Wells F, Chapman IM, Tonkin A \& Horowitz M (2001) Guar gum reduces postprandial hypotension in older people. J Am Geriatr Soc 49, 162-167. 
Kuipers HM, Jansen RW, Peeters TL \& Hoefnagels WH (1991) The influence of food temperature on postprandial blood pressure reduction and its relation to substance-P in healthy elderly subjects. J Am Geriatr Soc 39, 181-184.

Mathias CJ, da Costa DF, McIntosh CM, Fosbraey P, Bannister R, Wood SM, Bloom SR \& Christensen NJ (1989) Differential blood pressure and hormonal effects after glucose and xylose ingestion in chronic autonomic failure. Clin Sci (Lond) 77, $85-92$.

O’Donovan D, Feinle C, Tonkin A, Horowitz M \& Jones KL (2002) Postprandial hypotension in response to duodenal glucose delivery in healthy older subjects. J Physiol 540, 673-679.

O'Donovan D, Feinle-Bisset C, Chong C, Cameron A, Tonkin A, Wishart J, Horowitz M \& Jones KL (2005) Intraduodenal guar attenuates the fall in blood pressure induced by glucose in healthy older adults. J Gerontol 60A, 940-946.

Piha SJ (1991) Cardiovascular autonomic reflex tests: normal responses and age-related reference values. Clin Physiol 11, $277-290$.

Potter JF, Heseltine D, Hartley G, Matthews J, MacDonald IA \& James OF (1989) Effects of meal composition on the postprandial blood pressure, catecholamine and insulin changes in elderly subjects. Clin Sci (Lond) 77, 265-272.

Routledge HC, Chowdhary S, Coote JH \& Townend JN (2002) Cardiac vagal response to water ingestion in normal human subjects. Clin Sci (Lond) 103, 157-162.
Shannon JR, Diedrich A, Biaggioni I, Tank J, Robertson RM, Robertson D \& Jordan J (2002) Water drinking as a treatment for orthostatic syndromes. Am J Med 112, 355-360.

Sidery MB, Cowley AJ \& MacDonald IA (1993) Cardiovascular responses to a high-fat and a high-carbohydrate meal in healthy elderly subjects. Clin Sci (Lond) 84, 263-270.

Smith NL, Psaty BM, Rutan GH, Lumley T, Yanez D, Chaves PH \& Kronmal RA (2003) The association between time since last meal and blood pressure in older adults: the cardiovascular health study. J Am Geriatr Soc 51, 824-828.

Stevens MJ, Edmonds ME, Mathias CJ \& Watkins PJ (1991) Disabling postural hypotension complicating diabetic autonomic neuropathy. Diabet Med 8, 870-874.

Visvanathan R, Chen R, Garcia M, Horowitz M \& Chapman I (2005) The effects of drinks made from simple sugars on blood pressure in healthy older people. Br J Nutr 93, 575-579.

Visvanathan R, Chen R, Horowitz M \& Chapman I (2004) Blood pressure responses in healthy older people to $50 \mathrm{~g}$ carbohydrate drinks with differing glycaemic effects. Br J Nutr 92, 335-340.

Vloet LC, Mehagnoul-Schipper DJ, Hoefnagels WH \& Jansen RW (2001) The influence of low-, normal-, and high-carbohydrate meals on blood pressure in elderly patients with postprandial hypotension. J Gerontol 56A, M744-M748.

Waaler BA \& Eriksen M (1992) Post-prandial cardiovascular responses in man after ingestion of carbohydrate, protein or fat. Acta Physiol Scand 146, 321-327. 